\title{
Physiological Complications are Related with Gestational time Associated Maternal Ages- a Survey Based Research
}

\author{
Kazi Nadim Hossain ${ }^{1}$, Sajal Biswas ${ }^{1}$, Sheikh Hasibur Rahman ${ }^{1}$, Subroto Sarker ${ }^{1}$ and Debendra Nath Roy ${ }^{2 *}$ \\ ${ }^{1}$ Department of Pharmacy, Bangabandhu Sheikh Mujibur Rahman Science and Technology University, Bangladesh \\ ${ }^{2}$ Department of Pharmacy, Jessore University of Science and Technology, Bangladesh
}

Submission: December 01, 2016; Published: December 12, 2016

"Corresponding author: Debendra Nath Roy, Department of Pharmacy, Jessore University of Science and Technology, Jessore-7408, Bangladesh, Tel:+8801727663520; Fax: +880421-61199; Email: dn.roy@just.edu.bd/roydn009@gmail.com

\begin{abstract}
A woman's ability to adapt to the changes and challenges of pregnancy is unique and the level of the stress she experiences affects the outcome of pregnancy. Long term complication in pregnancy is an important health problem as it often occurs in the context of poor social support and maternal wellbeing. Complications and risks associated with pregnancy among women have been addressed in numerous studies from different viewpoints; mostly focusing on the medical risks associated with higher maternal age. Present study was carried out to expand the knowledge base regarding the potential physiological and psychological complications faced by women during the stage of pregnancy at different wedding ages. Our current showed that, although above $60 \%$ were observed no preexisting history, but around $60 \%$ complications started for those mothers who were less than 18 years and $31 \%$ among them became pregnant in 0 to 6 month after marriage. Hypertension was found to have $25 \%$ followed by $15 \%$ anemia and about $60 \%$ mothers have got married bellow 18 years old, though most of them are not highly educated and only $31 \%$ passed junior high school level. Therefore, a routine screening of pregnancy complication needs to be integrated into prenatal care. Specific interventions to minimize adverse labour outcomes could be a future research area.
\end{abstract}

Keywords: Complication; Physiological; Psychological; Maternal

\section{Introduction}

Maternal age was defined as the age of the mother in completed years at the time of birth because many of the outcomes were delivery related. Pregnancy, as a period in women's lives, is characterized by profound changes at all levels: physical, hormonal and psychological [1,2]. Understanding the impact of psychological problems faced by pregnant women, on their mental health and pregnancy, is vital for the wellbeing of the mother and the child. While pregnancy is often considered as the golden period in a woman's life, there are a host of physical as well as mental challenges faced by them then, which usually go unnoticed. Although pregnancy and childbirth have gained some recognition, as significant risk factors in the development and exacerbation of mental health issues, most women are still unaware of the devastating effect of these conditions. The degree of psychological stress associated with the process will vary depending on the women's developmental experiences, current life situation, and ability to adapt [3]. Though, psychological problems continued through first trimester to third trimester, overall among $14.1 \%$ of women were to be found suffering from psychiatric disorders during their second trimester, specially depression $3.3 \%$ to $6.9 \%$ and anxiety disorders $6.6 \%[4,5]$, panic disorder $2.5 \%$ [6]. Most researches in this area have focused on anxiety and depressive symptoms [7], rather than other psychiatric problems. During pregnancy, especially in the third trimester, sleep disorders are quite common [8]: increased snoring (11-16\%), restless legs symptoms (18-31\%), and impaired subjective sleep quality (39-54\%). Not only is sleep altered during pregnancy but dreaming is also affected with dreaming defined as subjective experiences occurring during sleep [9].

As a matter of fact, nearly $20 \%$ of women suffer from mood or anxiety disorders during the gestation and postpartum periods, with the women with a previous history of mental problems being at an increased risk. However whether the 
condition affects the woman during pregnancy or post it, it can cause significant morbidity for the mother as well as the child. It is therefore vital that the patient be well informed about the risks involved on both sides and take into account her specific diagnosis and the recommendations of the health care provider. It has been said that pregnant women and healthcare providers understand the risks differently: pregnant women evaluate the risks subjectively, through their own experiences, whereas healthcare providers assess the risks in an apparently more objective way [10].

Advanced maternal age is seen by patients and healthcare professionals, to be correlated with poorer outcomes to pregnancies. This is largely because of the higher incidence of chronic medical conditions among older women. Women of advanced maternal age are often treated as if they are in need of the level of care necessary for any high-risk pregnancy; and they are treated differently even if there is no scientific basis for different treatment and there are no medical problems evident. However, pre-existing and pregnancy-related morbidity, combined with high maternal expectations, does put these women in greater need of intervention during pregnancy and birth [11]. Despite the perceptions of increased risks related maternal age, it has been suggested that the risks are manageable and positive outcomes can be expected [12].

In recent years, several reviews concerning pregnant women aged 35 years or older have been conducted, which have focused on: the risks associated with advanced maternal age [13]; the relationship between maternal age and pregnancy outcomes $[12,14]$; the evidence of risks faced by women of advanced maternal age [15]; and the association between maternal age and still-birth [16]. The degree of acceptance is reflected in the woman's readiness for pregnancy and her emotional responses. The woman's attitude toward her pregnancy may be one of pride, acceptance, rejection or ambivalence. If the woman sees her pregnancy as an illness, she may perceive herself as unattractive, vulnerable, and uncomfortably dependent on other. These negative self-attitudes are likely to produce increased anxiety and irritability, which are then cycled through changes in the bloodstream to the fetus [17]. This survey based research aims to ascertain the main maternal complications in young women under the age of 18 years to till over 30 years, and examine whether they differ from causes of having conception at different time of marriage.

\section{Materials and Methods}

\section{Study area, study design and allocation of groups}

We performed a retrospective, cross-sectional study during 05 March, 2016 to 10 August, 2016 in two adjacent district named Jessore and Gopalgonj in Bangladesh. The total investigated patients were categorized into four groups in accordance with their marriage ages as
a) Group A - below 18 years
b) Group B - 18- 24 years
c) Group C - 25- 30 years
d) Group D - > 30 years

\section{Samples and data collection}

We first assessed the prescriptions and found out the name and age of participants. Data were collected by using set of questionnaires from maternal to carry out the survey. Total 200 pregnant mothers were investigated according their marriage aged below 18 years to more than 30 years by visiting major at home, hospitals and diagnostic centers across the study area. The data collectors were waiting to convince them to produce their prescription data to the interviewers as well as participated in the interview session. The patients who were unconscious/ mentally retarded, who were suffering with psychiatric diseases and who were admitted into hospitals were excluded from the study. Few questionnaires were excluded during the data analysis because of inadequate information.

\section{Statistical analysis}

By using Microsoft Excel (2013 addition) software, the collected data were statistically analyzed.

\section{Results and Discussion}

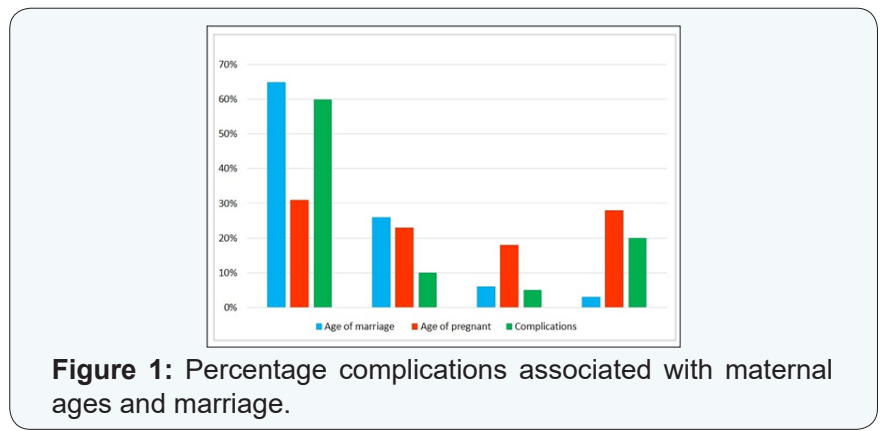

Women during their first pregnancy dreamed more often about their pregnancy than women who have borne more than one child [18]. Among the four categories top most $60 \%$ experiences complication for those, who have got married just under 18 years and became pregnant within 06 months of marriage, $10 \%$ experiences complication for 18-24 years old and became pregnant in 6-12 months of their marriage, $5 \%$ were for 25-30 years old and they have got concept within 1-2 years of marriage. On the other hand, this value is significantly increasing those mother who have got married after 30 years and is almost $20 \%$ complications rate though this is much less that of under 18 years. The result is shown in Figure 1. High blood pressure complication during pregnancy was observed for at least $25 \%$ cases followed by $15 \%$ for perineal tearing and anemia, about $10 \%$ for deep vein thrombosis and pelvic girdle pain, 7\% for infections and depression was observed for $5 \%$ mothers as shown in Figure 2. In case of preexisting severe 
medical conditions, no such experiences were observed above $50 \%$ respondents, and minor infection was present $33 \%$ cases as represented in Figure 3.
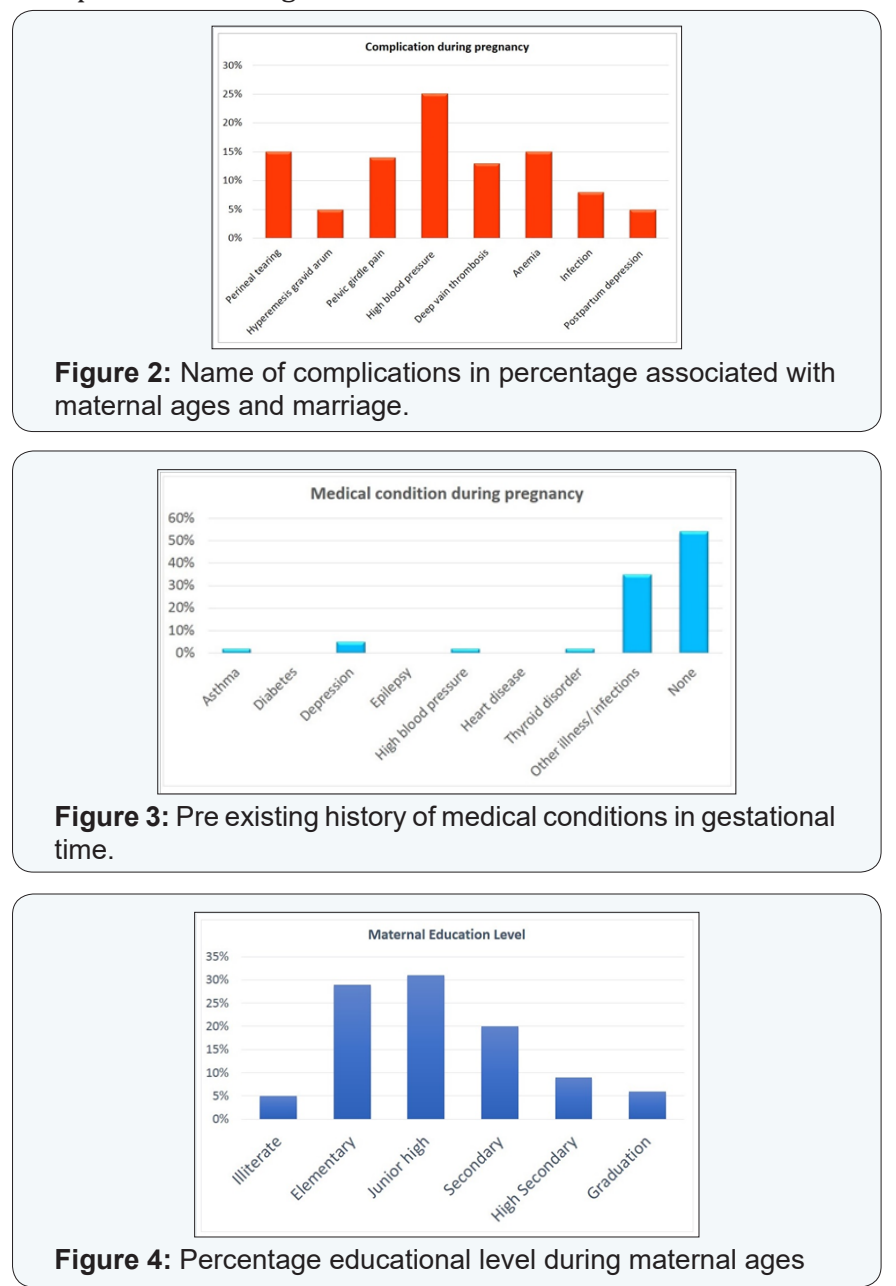

Figure 4: Percentage educational level during maternal ages

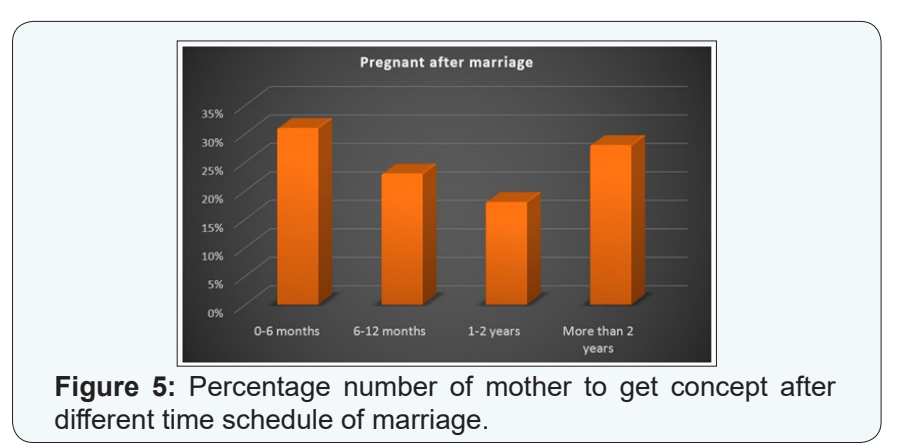

From our current study, it was observed that in case of educational status the majority $31 \%$ has completed junior high school level. $31 \%$ were got concept just within 0-6 months after weeding. 28\%, 23\% and 18\% were for more than 2 years, $6-12$ months and 1-2 years respectively. These results are shown in Figure $4 \& 5$. The percentage of the age of respondents can be summarized as follows- age among 15-20 years respondents was $42 \%$, age among 21-25 years respondents was $35 \%$, age among 25-30 years respondents was 20\%, age above 30 years respondents was only $3 \%$. The major number of respondent's age was among 15-20 years. Both men and women lack knowledge concerning conception, pregnancy complications, and infant outcomes as related to delayed childbearing [19]. In general, both men and women should be much better informed about the complications and declining fertility associated with a first pregnancy [20].
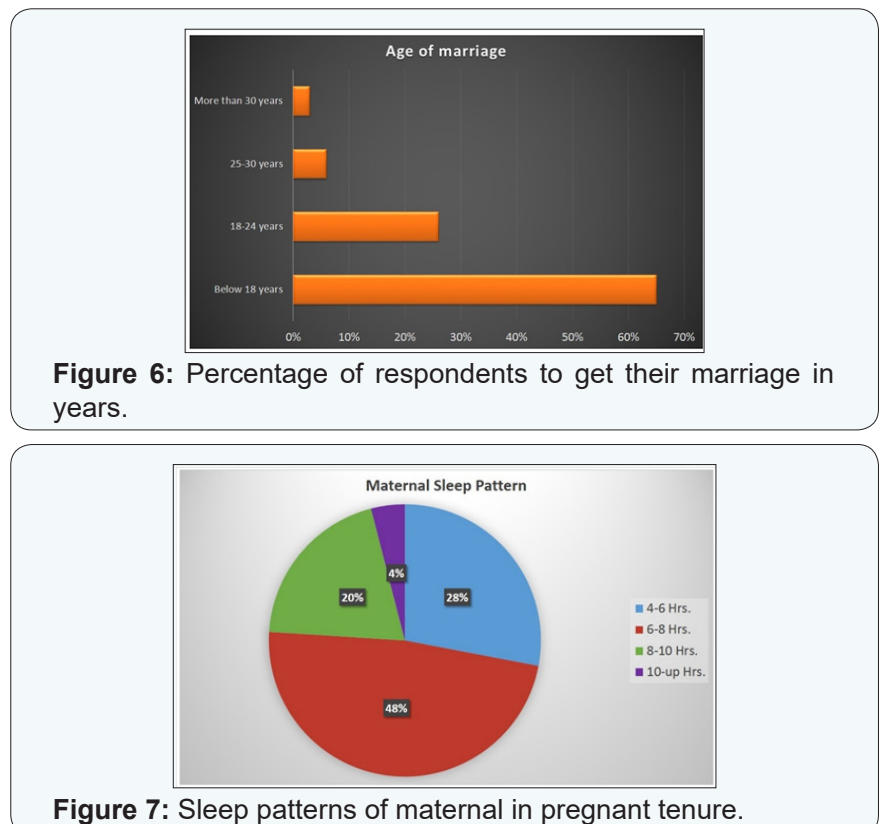

During collection data, we have found that $65 \%$ women got married bellow 18 years old, $26 \%$ women got married among 18-24 years old, $6 \%$ women got married among 25-30 years old, only $3 \%$ get married above 30 years old as the result is shown in Figure 6. Uninterrupted sleeping is another component of sound health during pregnancy period. In our study, $48 \%$ mother have got 6-8 hours sleeping time, while sleeping time of $28 \%$ are $4-6$ hours as shown in Figure 7. As a matter of fact, nearly all women suffer from mood or anxiety disorders during the gestation and postpartum periods, with the women with a previous history of mental problems being at an increased risk. However, whether the condition affects the woman during pregnancy or post it, it can cause significant morbidity for the mother as well as the child. It is therefore vital that the patient be well informed about the risks involved on both sides and take into account her specific diagnosis and the recommendations of the health care provider

\section{Conclusion}

While the main causes of maternal mortality in low and middle income countries are well understood, the main causes of maternal mortality for women of all ages are well documented. A recent systematic review [21] suggests that around three quarters of all maternal deaths globally are a result of direct obstetric causes: hemorrhage is the leading global cause of maternal death (27\% of all maternal deaths) followed by hypertensive disorders (14\%) and sepsis (10\%). When 
compared with causes of death for older women, hypertensive disorders were found to be a more important cause of mortality for adolescents in a number of studies in a range of settings. While the main causes of maternal death for women of all ages were similar across all regions, the study found significant regional variation for the proportion each cause contributes to total maternal mortality. Around $27 \%$ of maternal deaths for all ages are from indirect causes, but less is known about the specific conditions that contribute to this figure [22].

There is evidence that the relative importance of specific causes may differ for this younger age group compared to women over the age of 30 years. Women would clearly be benefited from support before and after childbirth it is advisable that before taking any medicine to reduce or eliminate such problems, a health care provider is consulted and should be explained the risks of medication to the unborn child or the infant through breast milk. This study highlights the paucity of evidence on complications associated maternal time, and emphasizes the need for greater efforts to collate and analyze data on agespecific causes of maternal problems. Since gestational health and pregnancy are synonymous with the wellbeing the mother and the child, women should formulate a treatment plan to manage these common problems.

\section{Acknowledgement}

We are grateful to all the reputed physicians, authority of hospitals, diagnostic centers and maternal mother's of Jessore and Gopalgonj district for providing us the necessary prescription and information's. We must pay out heartfelt thanks to the department of Pharmacy in Jessore University of Science and Technology and Bangabandhu Sheikh Mujibur Rahman Science and Technology University forinitiating important guidelines to complete this survey based research work successfully.

\section{Ethical Considerations}

The study was conducted following the general principles of World Medical Association (WMA) declarations of Helsinki and which was performed in collaboration with both the patients and their physicians with full consent of patients. This research work is logistically supported by the department of Pharmacy, Jessore University of Science and Technology, Jessore-7408 in Bangladesh. The human subjects involved in this study did not use any hazardous agents and samples were not collected from them. As the human subjects only participated in the interview, this survey based research didn't take any further approval from institutional ethics committee.

\section{References}

1. Avise JC (2013) Evolutionary perspectives on pregnancy. Columbia University Press, New York, USA, pp. 346.

2. Raphael-Leff J (1991) Psychological processes of childbearing Chapman and Hall, London, UK.
3. Novak JC, Broom BL (1995) Ingalls \& Sallerno's maternal and child health nursing, $\left(8^{\text {th }}\right.$ edn $)$. Mosby, St Louis, Missouri.

4. Andersson L, Sundstrom-Poromaa I, Bixo M, Wulff M, Bomdestam K, et al. (2003) Point prevalence of psychiatric disorders during the second trimester of pregnancy: a population-based study. Am J Obstet Gynecol 189(1): 148-154.

5. Bunevicius R, Kusminskas L, Bunevicius A, Nadisauskiene RJ, Jureniene $\mathrm{K}$, et al. (2009) Psychosocial risk factors for depression during pregnancy. Acta Obstet Gynecol Scand 88(5): 599-605.

6. Guler O, Sahin FK, Emul HM, Ozbulut O, Gecici O, et al. (2008) The prevalence of panic disorder in pregnant women during the third trimester of pregnancy. Comprehensive Psychiatry 49(2): 154-158.

7. Littleton HL, Breitkopf CR, Berenson AB (2007) Correlates of anxiety symptoms during pregnancy and association with perinatal outcomes: a meta-analysis. Am J Obstet Gynecol 196(5): 425-432.

8. Mindell JA, Cook RA, Nikolovski J (2015) Sleep patterns and sleep disturbances across pregnancy. Sleep Med 16(4): 483-488.

9. Schredl M (2014) Sleep and dreaming. In: Bassetti CL, et al. (Eds) ESRS European sleep medicine textbook. European Sleep Resarch Society (ESRS), Regensburg, Germany, p. 63-71.

10. Carolan MC (2009) Towards understanding the concept of risk for pregnant women: some nursing and midwifery implications. J ClinNurs 18(5): 652-658.

11. Braveman FR (2006) Pregnancy in patients of advanced maternal age. Anesthesiol Clin 24(3): 637-646.

12. Carolan M (2003) The graying of the obstetric population: implications for the older mother. J ObstetGynecol Neonatal Nurs 32(1): 19-27

13. Aref-Adib M, Freeman-Wang T, Ataullah I (2008) The older obstetric patient. Obstetrics, Gynaecology \& Reproductive Medicine 18(2): 4348.

14. Newburn-Cook CV, Onyskiw JE (2005) Is older maternal age a risk factor for preterm birth and foetal growth restriction? A systematic review. Health Care Women Int 26(9): 852-875.

15. Suplee PD, Dawley K, Bloch JR (2007) Tailoring peripartum nursing care for women of advanced maternal age. J Obstet Gynecol Neonatal Nurs 36(6): 616-623.

16. Huang L, Sauve R, Birkett N, Fergusson D, van Walraven C (2008) Maternal age and risk of still birth: a systematic review. CMAJ 178(2): 165-172.

17. De Muyider X (1989) Psychological factors and preterm labor. Journal of Reproductive \& Infant Psychology 7(1): 55-57.

18. Blake RL, Reimann J (1993) The pregnancy-related dreams of pregnant women. J Am Board Fam Pract 6(2): 117-122.

19. Tough S, Benzies K, Fraser-Lee N, Newburn-Cook C (2007) Factors influencing childbearing decisions and knowledge of perinatal risks among Canadian men and women. Matern Child Health J 11(2): 189198.

20.Zasloff E, Schytt E, Waldenstrom U (2007) First time mothers' pregnancy and birth experiences varying by age. Acta Obstet Gynecol Scand 86(11): 1328-1336.

21. Say L, Chou D, Gemmill A, Tunçalp Ö, Moller AB, et al. (2014) Global causes of maternal death: a WHO systematic analysis. Lancet Glob Health 2(6): e323-e333.

22. Storm F, Agampodi S, Eddleson M, Sorenson JB, Flemming Konradsen, et al. (2014) Indirect causes of maternal death. Lancet Glob Health 2(10): e566. 


\begin{tabular}{|l|}
\hline \multicolumn{1}{|c|}{ Your next submission with JuniperPublishers } \\
will reach you the below assets \\
- Quality Editorial service \\
- Swift Peer Review \\
- Reprints availability \\
- E-prints Service \\
- Manuscript Podcast for convenient understanding \\
- Global attainment for your research \\
- Manuscript accessibility in different formats \\
( Pdf, E-pub, Full Text, Audio) \\
- Unceasing customer service \\
Track the below URL for one-step submission \\
http://juniperpublishers.com/online-submission.php \\
\hline
\end{tabular}

